\title{
ANALYTICAL METHOD DEVELOPMENT AND VALIDATION STUDIES OF TICAGRELOR TABLETS BY RP-HPLC
}

\author{
K. TABASSUM1 ${ }^{*}$, R. SARVESH² \\ ${ }^{1}$ SVKM's Dr. Bhanuben Nanavati College of Pharmacy, Mumbai, India, ${ }^{2}$ Alkem Laboratories, Mumbai, India \\ Email: tabassum.khan@bncp.ac.in
}

Received: 28 Jan 2017, Revised and Accepted: 14 Jun 2017

\begin{abstract}
Objective: The present study was conducted to develop a simple and precise analytical method for the estimation of ticagrelor in tablet formulation.

Methods: Reverse Phase HPLC was used for method development and validation studies of ticagrelor. The optimum chromatographic conditions comprised of C18 column (Kromasil, $250 \times 4.6 \mathrm{~mm}, 5 \mu$ ) as the stationary phase and aqueous buffer (containing $0.5 \mathrm{ml}$ formic acid and triethylamine each in water) and acetonitrile in the ratio of $50: 50 \mathrm{v} / \mathrm{v}$ as the mobile phase. The flow rate was $1.3 \mathrm{ml} / \mathrm{min}$ with detection at $256 \mathrm{~nm}$ and a run time of 6 min. Forced degradation studies were conducted and the isocratic mode was modified to a gradient mode to make the method stability
\end{abstract} indicating in nature.

Results: The retention time of ticagrelor was $3.372 \mathrm{~min}$. The linearity studies indicated that the range of the developed method was 20 -90 ppm with a correlation coefficient of 0.9956 . The method was specific with a percent mean recovery was found to be $99.93 \%$.. The $\%$ RSD in the precision studies was 0.069 . The validated method was applied to conduct the assay of ticagrelor in tablets and the with a percent mean recovery of $99.82 \%$. The modified method was capable of resolving 13 related substances from the ticagrelor peak in the forced degradation studies.

Conclusion: The developed and validated RP-HPLC isocratic method was simple, accurate and precise as per the ICH guidelines. It was suitable for the analysis of ticagrelor in bulk and tablet formulation. The modified gradient method can be used to resolve the in-process impurities and related substances and can be directly applied to liquid chromatography hyphenated with mass spectroscopy (LC/MS) studies with minor modifications for identification of related substances.

Keywords: RP-HPLC, Agilent 1260 UV/PDA, Ticagrelor, Kromasil C18, Related substances, Forced degradation

(C) 2017 The Authors. Published by Innovare Academic Sciences Pvt Ltd. This is an open access article under the CC BY license (http://creativecommons.org/licenses/by/4.0/) DOI: http://dx.doi.org/10.22159/ijap.2017v9i4.17440

\section{INTRODUCTION}

Chromatography is a powerful separation method that finds application in all branches of science which is used for method development. High Performance Liquid Chromatography or High Pressure Liquid Chromatography (HPLC) is mainly a chromatography technique that can separate a mixture of compounds and is used in biochemistry and analytical chemistry to identify, quantify and purify the individual components of a mixture of analytes by distributing between the mobile phase (a flowing liquid) and a stationary phase (sorbents packed inside a column). Ticagrelor is newly introduced into the market, hence the data on the qualitative and quantitative estimation of this drug is limited. It is marketed as a tablet for the treatment of thrombosis. It reduces the rate of thrombotic cardiovascular events in patients with the acute coronary syndrome. It belongs to the class of triazolo pyrimidines which are polycyclic aromatic compounds containing triazole ring fused to a pyrimidine ring. Ticagrelor and its major metabolite reversibly interact with the platelet $\mathrm{P}_{2} \mathrm{Y}_{12}$ ADP-receptor to prevent signal transduction and platelet activation. It is a white crystalline powder with an aqueous solubility of approximately $10 \mu \mathrm{g} / \mathrm{ml}$ at room temperature. It has a $\log \mathrm{P}$ of 2.30 , pKa of strong acidic function 12.94 and strong basic function 2.90 . It prevents platelet aggregation and thrombus formation in atherosclerotic disease which reduces chances of cardiac arrest due to blockage [1]. The marketed formulation of ticagrelor replaced clopidogrelcontaining formulations due to higher efficacy and lower side effects. It was approved for use in the European Union by the European Commission on December 3, 2010, by the US Food and Drug Administration on July 20, 2011. This antiplatelet drug formulation was developed and marketed by AstraZeneca, the patent was granted on $10^{\text {th }}$ June 2008 and patent expire on $3^{\text {rd }}$ December 2018. The clinical evidence for the effectiveness of ticagrelor was derived from Plato, a randomized double-blind study comparing ticagrelor with clopidogrel. This product is used to treat people who have had a recent heart attack or severe chest pain that happened because their heart was not getting enough oxygen or are treated with a procedure to open blocked arteries in the heart [2-4]. A literature search revealed very few papers on analytical methods of this drug. One research paper has reported a UV method of analysis and another one has reported a HPLC method of analysis for ticagrelor using UV detector [5-6]. Hence the aim of this study was to develop a simple, accurate and precise RP-HPLC analytical method for the estimation of ticagrelor in tablet formulation.

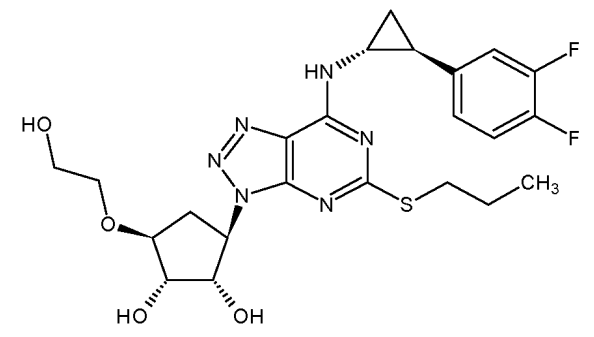

Fig. 1: Chemical structure of ticagrelor

\section{MATERIALS AND METHODS [7-9]}

\section{Chemicals and reagents}

Ticagrelor reference standard was obtained as a gift sample from Watson® Pharmaceuticals. Methanol and acetonitrile (HPLC grade), MilliQ water. hydrochloric acid (AR) 37\%, sodium hydroxide (AR grade), orthophosphoric acid (HPLC grade) 85\%, ammonium acetate (GR), potassium dihydrogen phosphate (AR), hydrogen peroxide (ACS) $50 \%$, formic acid (AR), triethylamine (HPLC grade), sodium 
lauryl sulphate, polysorbate 80 (GR) were procured from Merck® and Fischer Scientific®.

\section{Instruments used}

The HPLC system used was an Agilent 1260 infinity equipped with a quaternary solvent pump, a thermostated autosampler, degasser, UV/VWD detector and a column oven. A double beam UV-Visible spectrophotometer (Shimadzu 1800), USP Type II-Paddle apparatus (Labindia DS2000 with Ismatec high precision multichannel pump as autosampler), photo stability chamber (Atlas Suntest XLS+), HPLC water purifier (Millipore-Merck Millipore), orbital shaker (Thermo scientific) and a centrifuge (REMI research centrifuge) were used for this analysis.

\section{Preparation of solutions}

UV studies

\section{Preparation of standard stock solution (10 ppm)}

$1 \mathrm{mg}$ of ticagrelor reference standard was weighed accurately and transferred into a $100 \mathrm{ml}$ volumetric flask. $30 \mathrm{ml}$ diluent (acetonitrile: water 90:10 v/v) was added and the mixture was sonicated. The solution was diluted up to the mark with the diluent to give the standard stock solution. The $\lambda_{\max }$ was determined using UV-VIS spectrophotometer. A working standard range from 2 to 7 ppm was prepared from the stock solution of $10 \mathrm{ppm}$ and used for linearity studies.

\section{Preparation of standard stock solution (90 ppm)}

$25.0 \mathrm{mg}$ of ticagrelor reference standard was weighed and transferred into a $25 \mathrm{ml}$ volumetric flask to obtain a solution of 1000 ppm in duplicate. $18 \mathrm{ml}$ of methanol was added and sonicated. This solution was diluted to volume with methanol and mixed well. 9.0 $\mathrm{ml}$ of standard stock solution was taken and diluted to $100 \mathrm{ml}$ with diluent to give a standard stock solution of $90 \mathrm{ppm}$.

\section{Preparation of sample solution}

Five tablets of ticagrelor were weighed and transferred to $250 \mathrm{ml}$ volumetric flask. $100 \mathrm{ml}$ of water was added and sonicated for $1 \mathrm{~h}$ to disperse the contents. Further $50 \mathrm{ml}$ of water was added and the flask was kept in an orbital shaker at $50 \mathrm{rpm}$ for $2 \mathrm{~h}$ at room temperature (RT). The flasks were made up to the mark with water. The solution was then filtered using a $0.45 \mu$ Whatman Teflon filter. The filter was saturated by discarding the first $10 \mathrm{ml}$ of filtrate. 5.0 $\mathrm{ml}$ of the above filtrate was further diluted to $100 \mathrm{ml}$ with diluent and mixed well to get the desired concentration.

\section{Preparation of buffers}

\section{Preparation of buffered mobile phase}

$0.5 \mathrm{ml}$ and $0.5 \mathrm{ml}$ of concentrated triethylamine solution were added using $1 \mathrm{ml}$ pipette to $500 \mathrm{ml}$ water, filtered through $0.45 \mu$ Nylon 6,6 membrane filter under suction and sonicated to degas.

\section{Preparation of other buffers}

$6.8 \mathrm{~g}$ of potassium dihydrogen orthophosphate $\left(\mathrm{KH}_{2} \mathrm{PO}_{4}\right)$ was added, filtered through $0.45 \mu$ Nylon 6, 6 membrane filter under suction and sonicated to degas. The $\mathrm{pH}$ was adjusted and maintained using concentrated orthophosphoric acid (OPA) to get $\mathrm{pH} 3.0, \mathrm{pH} 4.5, \mathrm{pH}$ 6.8 and $\mathrm{pH} 7.5$ respectively.

$0.1 \%$ and $0.2 \%$ of sodium lauryl sulphate (SLS) media: $10 \mathrm{~g}$ and $20 \mathrm{~g}$ of SLS was dissolved in $10 \mathrm{~L}$ of water and sonicated. Similarly for preparing $0.1 \%$ and $0.2 \%$ of polysorbate (tween) media: $10 \mathrm{~g}$ and 20 $\mathrm{g}$ of tween 80 were dissolved in $10 \mathrm{~L}$ of water and sonicated.

\section{Filter compatibility studies}

Filter compatibility tests were conducted to get a particle-free solution, which also should reproduce $100 \%$ response as per the respective content. The filtrate from each filter was compared with the centrifuged sample. The filter complying with all the parameters and showing same concentration as that of centrifuged sample was selected for further studies.

Five intact tablets were weighed and transferred to $250 \mathrm{ml}$ volumetric flask. $25 \mathrm{ml}$ of miliQ water was added and sonicated for $10 \mathrm{~min} .150 \mathrm{ml}$ of acetonitrile was added and sonicated for 20 min with intermittent swirling. This was further diluted with acetonitrile mixed and filtered using $0.45 \mu$ Whatman Teflon filter. $10 \mathrm{ml}$ of filtrate was discarded and further $5 \mathrm{ml}$ was diluted to $100 \mathrm{ml}$ with diluent. A $20 \mathrm{ml}$ aliquot was subjected to centrifuge at $5000 \mathrm{rpm}$ for $20 \mathrm{~min}$ and another $20 \mathrm{ml}$ per filter was passed through the filters listed in fig. 2 .

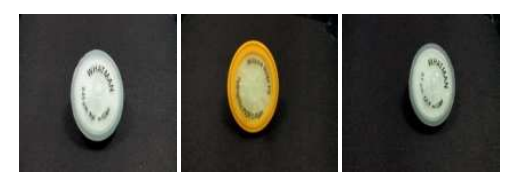

Fig. 2: Filter study-Whatman $0.45 \mu \mathrm{m}$ Nyl w/GMF, Whatman 0.7 $\mu \mathrm{m}$ GF/F w/GMF, Millipore millex-HV Hydrophilic PVDF 0.45 $\mu \mathrm{m}$ respectively

The four solutions were chromatographed and were compared for peak shape and peak area. The filter that matched the centrifuged sample data was selected for further studies.

Selection of diluent (HPLC compatible solvent) and solution stability studies

The stability of the solution under study was established by keeping the solution at room temperature for $24 \mathrm{~h}$. A standard solution was prepared using acetonitrile: water $(90: 10 \mathrm{v} / \mathrm{v}, 50: 50 \mathrm{v} / \mathrm{v}$, and 10: $90 \mathrm{v} / \mathrm{v})$, methanol: water (90: $10 \mathrm{v} / \mathrm{v}, 50: 50 \mathrm{v} / \mathrm{v}$ and $10: 90 \mathrm{v} / \mathrm{v})$. The samples were injected at different time intervals of $5 \mathrm{~min}, 1 \mathrm{~d}$ and $1 \mathrm{w}$.

\section{Selection of flow rate and load volume}

Flow rates $(0.8 \mathrm{ml} / \mathrm{min}$. and $1.3 \mathrm{ml} / \mathrm{min}$.) and loading volumes $(1,4$, $5,6,10,20,50 \mu \mathrm{l})$ were analyzed to get a precise and reproducible peak of ticagrelor with minimum tailing or fronting.

\section{Selection and optimization of mobile phase}

Various mobile phase compositions like acetonitrile: water (50: 50 $\mathrm{v} / \mathrm{v}, 90: 10 \mathrm{v} / \mathrm{v}, 60: 40 \mathrm{v} / \mathrm{v}, 40: 60 \mathrm{v} / \mathrm{v}$ and 10: $90 \mathrm{v} / \mathrm{v}$ ), acetonitrile: methanol: water (80: 10: $10 \mathrm{v} / \mathrm{v}, 50: 25: 25 \mathrm{v} / \mathrm{v}, 30: 40: 30 \mathrm{v} / \mathrm{v}, 40$ : 30: $30 \mathrm{v} / \mathrm{v}$ and 10: $45: 45 \mathrm{v} / \mathrm{v})$, acetonitrile: TEA buffer in water (50: $50 \mathrm{v} / \mathrm{v}$ ratio with $0.25 \mathrm{ml}$ and $0.5 \mathrm{ml}$ concentration of TEA per 500 ml.), acetonitrile: TEA and FA buffer in water (50: $50 \mathrm{v} / \mathrm{v}$ ratio with $0.25 \mathrm{ml}: 0.25 \mathrm{ml}$ and $0.5 \mathrm{ml}: 0.5 \mathrm{ml}$ concentration of TEA and FA per $500 \mathrm{ml}$.), acetonitrile: buffer [pH range 3 to 7.5] (50: $50 \mathrm{v} / \mathrm{v}, 80: 20$ $\mathrm{v} / \mathrm{v}$ and $20: 80 \mathrm{v} / \mathrm{v}$ ) were evaluated in an effort to get symmetrical, sharp and reproducible peaks of ticagrelor.

\section{Selection and optimization of stationary phase}

Using the temporary developed chromatographic method a variety of columns with different attributes like polarity, particle size (3.5 $\mu$ and $5 \mu$ ), carbon loading (C8 and C18) and dimensions were screened in an effort to arrive at the best column for the given analysis. Some of the

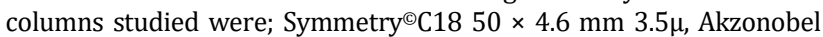
Kromasi ${ }^{\odot} \mathrm{C} 18150 \times 4.6 \mathrm{~mm} 5 \mu$, Waters Xterra ${ }^{\odot} \mathrm{C} 18150 \times 4.6 \mathrm{~mm}$ $3.5 \mu$, BDS Hypersil thermo ${ }^{\odot}$ C8 $50 \times 4.6 \mathrm{~mm} 5 \mu$, Fortis ${ }^{\oplus} \mathrm{C} 850 \times 4.6 \mathrm{~mm}$ $5 \mu$ and Agilent zorbax ${ }^{\odot} \mathrm{RX}$ C18 $150 \times 4.6 \mathrm{~mm}$, etc.

Selection of dissolution media by Biopharmaceutical Classification System (BCS)

A ticagrelor standard solution was prepared and the final dilution was done using water, $0.1 \mathrm{~N} \mathrm{HCl}$, pH 4.5 buffer, pH 6.8 buffer, SLS media and tween media respectively.

Five tablets were weighed and transferred to $250 \mathrm{ml}$ volumetric flask. $100 \mathrm{ml}$ of water was added and sonicated for $1 \mathrm{~h}$ to disperse the contents. Further $50 \mathrm{ml}$ of water was added and the flask was kept in an orbital shaker at $50 \mathrm{rpm}$ for $2 \mathrm{~h}$ at RT. The solutions were made up to the mark with water. The solutions were mixed well and filtered using $0.45 \mu$ whatman teflon filter. The filter was saturated by discarding $10 \mathrm{ml}$ of filtrate and $5.0 \mathrm{ml}$ of above solution was diluted to $100 \mathrm{ml}$ with diluent and mixed well. 
The $\%$ content of the ticagrelor into the respective media was calculated using formula;

$$
\frac{\mathrm{A}_{\mathrm{T}}}{\mathrm{A}_{\mathrm{S}}} \times \frac{\mathrm{W}_{\mathrm{S}}}{25} \times \frac{9}{100} \times \frac{250}{5} \times \frac{100}{5} \times \frac{\mathrm{P}}{100} \times \frac{100}{\mathrm{LC}}
$$

Where, $A_{\mathrm{T}}=$ Peak area response of ticagrelor in the chromatogram obtained from the test solution. As = Average peak area response of ticagrelor in the chromatograms obtained from replicate injections of standard solution. $\mathrm{W}_{\mathrm{S}}=\mathrm{Weight}$ of ticagrelor standard taken in $\mathrm{mg}$ in standard stock solution. $\mathrm{P}=\%$ Purity of ticagrelor standard. $\mathrm{LC}=$ Label claim of ticagrelor in mg per tablet.

Dissolution studies of ticagrelor tablets

Table 1: Dissolution testing conditions of ticagrelor tablets

\begin{tabular}{ll}
\hline Apparatus & USP type II (Paddle) \\
\hline Disso. volume & $900 \mathrm{ml}$ \\
Speed & $75 \mathrm{rpm}$ \\
Temperature & $37^{\circ} \mathrm{C}$ \\
Time (min.) & $5,10,20,30,45$ and 60. \\
\hline
\end{tabular}

Six tablets were weighed and transferred to 6 individual jars containing $900 \mathrm{ml}$ distilled water as dissolution media previously maintained at 37 ${ }^{\circ} \mathrm{C}$ and the dissolution apparatus was set as per dissolution testing conditions. At specified intervals of time, $10 \mathrm{ml}$ of sample aliquots were withdrawn and replenished with the same volume of fresh media. The samples were filtered with $0.45 \mu$ Whatman Teflon filter. Around $8 \mathrm{ml}$ of the sample was discarded to saturate the filter.

Similarly, the procedure was repeated using $0.1 \mathrm{~N} \mathrm{HCl}$, pH 4.5 buffer, pH 6.8 buffer, $0.1 \%$ SLS media, $0.2 \%$ SLS media and $0.1 \%$ Tween 80 media, $0.2 \%$ Tween 80 media.

The release of the ticagrelor into the respective media was calculated using formula;
Where, $A_{T}=$ Peak area response of ticagrelor in the chromatogram obtained from test solution, As = Average peak area response of ticagrelor in the chromatograms obtained from replicate injections of standard solution, $\mathrm{W}_{\mathrm{s}}=$ Weight of ticagrelor standard taken in $\mathrm{mg}$ in standard stock solution, $\mathrm{P}=\%$ Purity of ticagrelor standard, $\mathrm{LC}=$ Label claim of ticagrelor in mg per tablet.

\section{Assay of ticagrelor tablets}

Ticagrelor standard solution and ticagrelor sample solution were prepared as discussed in 2.5.1 and 2.5.2. The samples were analysed using the developed chromatographic method and the $\%$ content of the drug in the tablets was determined.

Table 2: Gradient sequence for related substances studies

\begin{tabular}{lll}
\hline Time (min) & \% acetonitrile & \% FA: TEA 1:1 v/v in water \\
\hline 0.00 & 45 & 55 \\
10.0 & 20 & 80 \\
20.0 & 50 & 50 \\
30.0 & 80 & 20 \\
40.0 & 45 & 55 \\
\hline
\end{tabular}

$0.1 \mathrm{mg}$ of known impurity (Acetal impurity, RS-13) was weighed accurately and transferred to $10 \mathrm{ml}$ volumetric flask. $5 \mathrm{ml}$ of diluent was added, sonicated and diluted to volume with diluent to get $10 \mathrm{ppm}$ of impurity solution. The chromatograms of ticagrelor reference standard, drug sample and known impurity solutions were compared using the above-mentioned gradient run.

\section{Related substances studies}

The isocratic mode of the RP-HPLC method was modified to a gradient mode as given below with a run time of 40 min.

\section{Forced degradation studies}

With slight modifications, the developed chromatographic method was used to get accurate results. The optimized chromatographic method was kept same and run time was $12.0 \mathrm{~min}$. Forced degradation studies of ticagrelor were conducted using solution stressors like distilled water, $0.1 \mathrm{~N} \mathrm{HCl}, 0.1 \mathrm{~N} \mathrm{NaOH}$, hydrogen peroxide $50 \%$. Photostability studies were conducted at a flux of 4.6 $\times 1014$ photons for $24 \mathrm{~h}$ and thermostability studies were conducted at a temperature of $80{ }^{\circ} \mathrm{C}$ for $24 \mathrm{~h}$. The results were compared with the untreated standards.

Five tablets were weighed accurately and transferred to $250 \mathrm{ml}$ volumetric flask. $25 \mathrm{ml}$ miliQ water was added and sonicated for 10 min. $150 \mathrm{ml}$ of acetonitrile was added and sonicated for $20 \mathrm{~min}$. with intermittent swirling. $25 \mathrm{ml}$ of respective stressor was added and heated at $80^{\circ} \mathrm{C}$ for $24 \mathrm{~h}$ on a water bath previously maintained at 80 ${ }^{\circ} \mathrm{C}$. The sample was cooled to RT and neutralized. It was filtered using $0.45 \mu$ Whatman Teflon filter. $10 \mathrm{ml}$ of filtrate was used for filter saturation and remaining $7 \mathrm{ml}$ was used. $5 \mathrm{ml}$ of filtrate was diluted to $100 \mathrm{ml}$ with diluent. The results were compared with the untreated sample. For the solid degradation analysis, the tablets were treated with the respective stressor and the results were compared with the untreated sample.

\section{Validation studies [10-15]}

\section{Accuracy}

The accuracy of the method was determined by calculating \% recovery. A known amount of ticagrelor was added to a placebo and the amounts were estimated by measuring the peak area. These studies were carried out in triplicate over the specified concentration range and the amount of ticagrelor was estimated by measuring the peak area ratios. The percentage recovery and standard deviation of percentage recovery were calculated.

\section{Precision}

The precision of the method was determined in terms of Intra-day and inter-day precision. For intra-day precision studies, a standard solution of $90 \mathrm{ppm}$ was injected at various time intervals and percent related standard deviation (\%RSD) was estimated.

The inter-day precision was studied by injecting the same concentration of standard solution on consecutive days and the $\%$ RSD of the signal was calculated. The repeatability, intermediate precision and reproducibility of the developed method were determined. 


\section{Specificity}

Specificity is the ability to assess unequivocally the analyte in the presence of components etc. The blank (diluent), placebo, standard (90 ppm), sample (90 ppm) were prepared and injected to prove that the method developed was specific to ticagrelor.

\section{Linearity and range}

The linearity of the method was determined at six concentration levels ranging from 1-7 ppm of ticagrelor. A regression line was plotted of peak area $\mathrm{v} / \mathrm{s}$ concentration. The correlation coefficient and equation of the regression line were calculated. The interval of lowest assessed concentration to the highest is the linearity range of the procedure.

\section{LOD and LOQ}

The detection limit of an individual analytical procedure is the lowest amount of analyte in a sample which can be detected but not necessarily quantitated as an exact value. The quantitation limit of an individual analytical procedure is the lowest amount of analyte in a sample which can be quantitatively determined with suitable precision and accuracy.

Where, $=$ the standard deviation of the response, Slope = slope of the calibration curve.

\section{Robustness}

Robustness of the developed method was studied by changing the flow rate and column temperature. The effect of flow rate was studied by keeping all chromatographic conditions same except the flow rate, i.e. $1.2 \mathrm{ml} / \mathrm{min}$ and in the next run $1.4 \mathrm{ml} / \mathrm{min}$ respectively.

Similarly, the effect of temperature was studied by keeping all chromatographic conditions same except the temperature, i.e. $35^{\circ} \mathrm{C}$ and in the next run with $25^{\circ} \mathrm{C}$ respectively.

\section{System suitability}

The system suitability parameters like retention time, the number of USP theoretical plates, USP tailing, peak area and peak height were evaluated.

\section{RESULTS AND DISCUSSION}

\section{UV studies}

The UV spectrum of ticagrelor in acetonitrile: water (90: $10 \mathrm{v} / \mathrm{v})$ indicated the $\lambda \max$ to be $256 \mathrm{~nm}$ (fig. 3a). The response was linear and the regression equation was found to be $\mathrm{y}=0.1331 \mathrm{x}+0.0858$. The coefficient of correlation $\left(\mathrm{R}^{2}\right)$ was found to be 0.9971 (fig. 3b).

\section{Filter compatibility studies}

A temporary chromatographic method was used for selection of the best filter. Whatman Nylon w/GMF membrane filter pore size of $0.45 \mu$ was selected after comparing the peak area and concentration (table 3) of centrifuged drug solution to other drug samples (fig. 4a and 4b). Based on these observations acetonitrile: water; 90: $10 \mathrm{v} / \mathrm{v}$ was selected as the diluent for further studies. The stability of drug sample was determined by keeping the sample in contact with the diluent for $5 \mathrm{~min}, 24 \mathrm{~h}$ and $1 \mathrm{w}$ which indicated no change in the concentration (fig. 5a-5c and table 4).

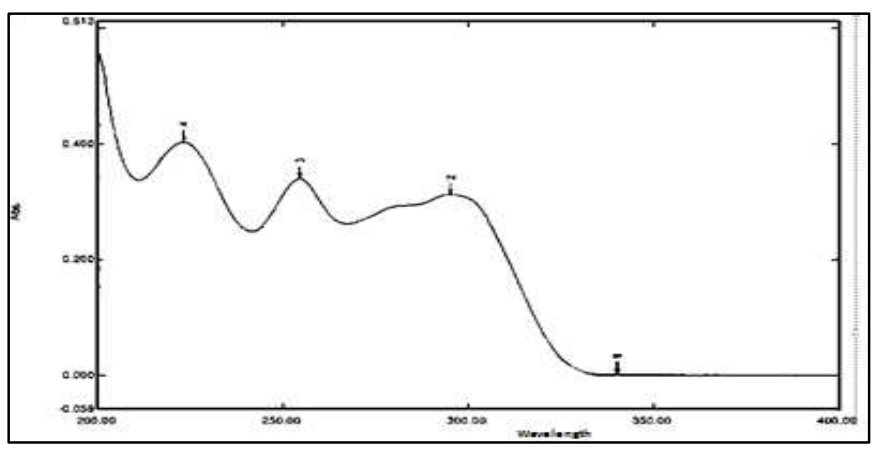

Fig. 3a: UV spectrum scan of ticagrelor in ACN: water (90: $10 \mathrm{v} / \mathrm{v})$

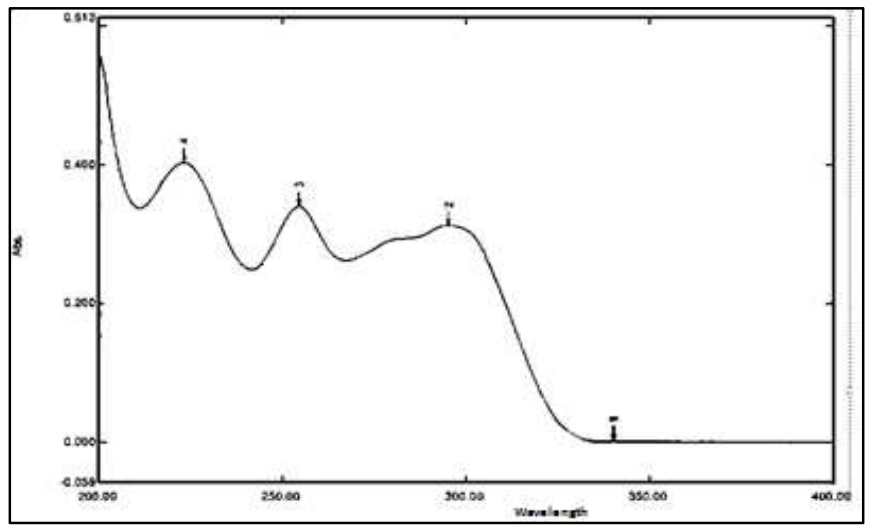

Fig. 3b: Calibration curve and $\mathrm{R}^{2}$ of ticagrelor

Table 3: Filter compatibility studies

\begin{tabular}{llll}
\hline S. No. & Sample analyzed from & Observation & peak area \\
\cline { 3 - 4 } & & Concentration (ppm) & 1134583 \\
\hline 1 & Centrifuge & 89.63 & 1134437 \\
2 & $0.45 \mu$ WhtNyl w/GMF & 89.62 & \\
\hline
\end{tabular}




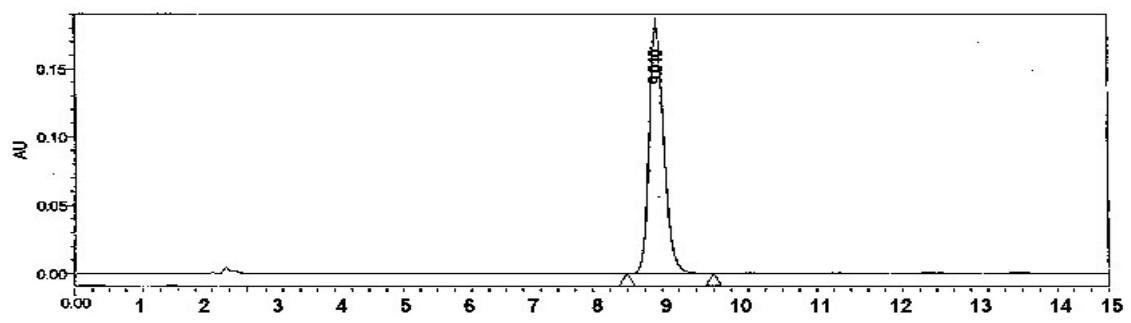

Fig. 4a: Chromatogram of the ticagrelor in the centrifuge solution

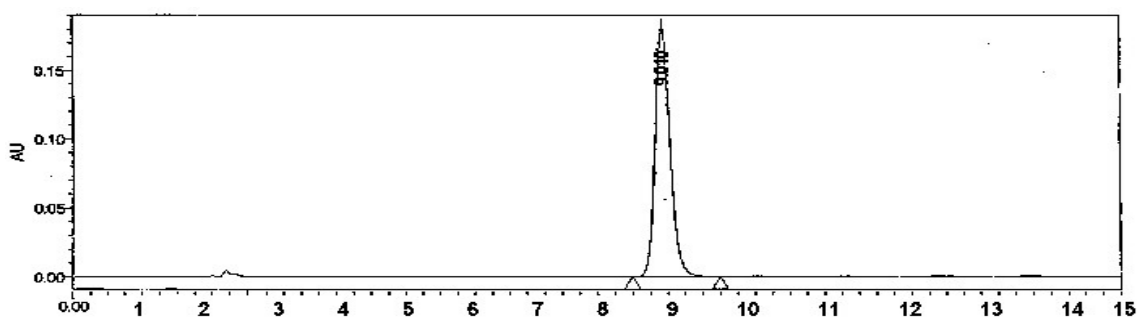

Fig. 4b: Chromatogram of the ticagrelor filtered through $0.45 \mu$ Whatman Nylon w/GMF membrane filter

Table 4: Effect of diluent on chromatogram after specified time intervals

\begin{tabular}{llll}
\hline S. No. & Analysis after & Observation & peak area \\
\cline { 3 - 4 } & & Retention time (min) & 1134437 \\
\hline 1 & $5 \mathrm{~min}$ & 9.010 & 1134430 \\
2 & $24 \mathrm{~h}$. & 9.010 & 1134432 \\
3 & $1 \mathrm{w}$ & 9.010 & 110 \\
\hline
\end{tabular}

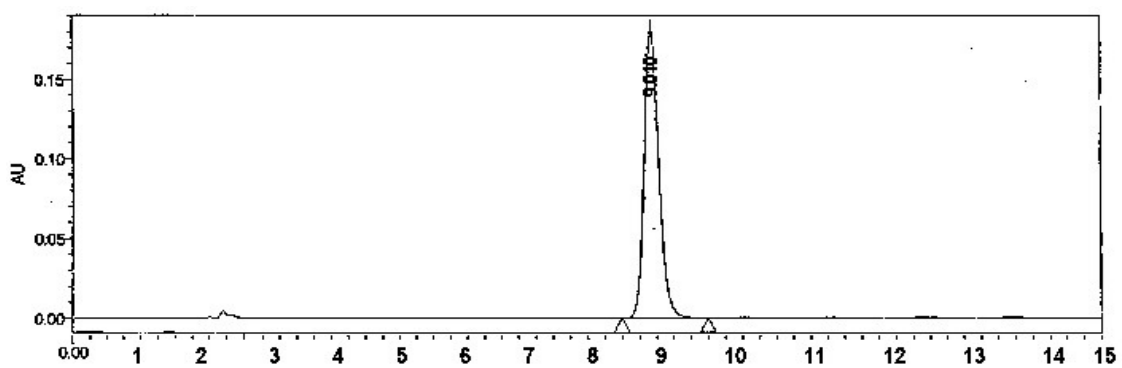

Fig. 5a: Chromatogram of ticagrelor standard solution after 5 min

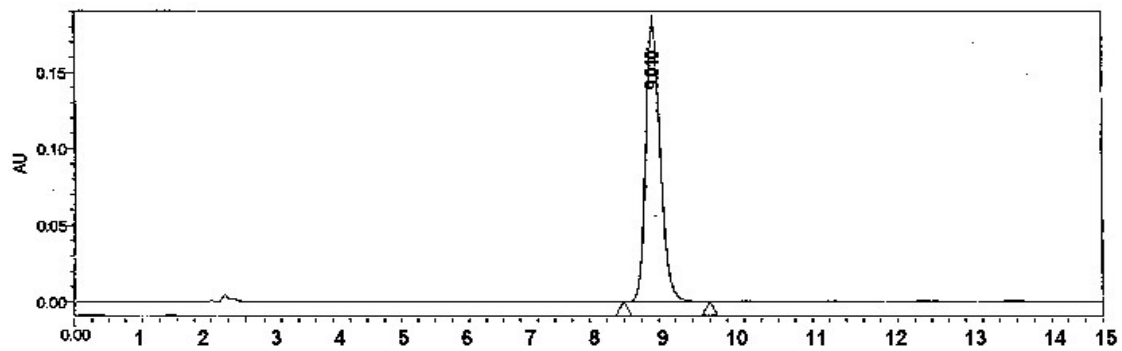

Fig. 5b: Chromatogram of ticagrelor standard solution after $24 \mathrm{~h}$

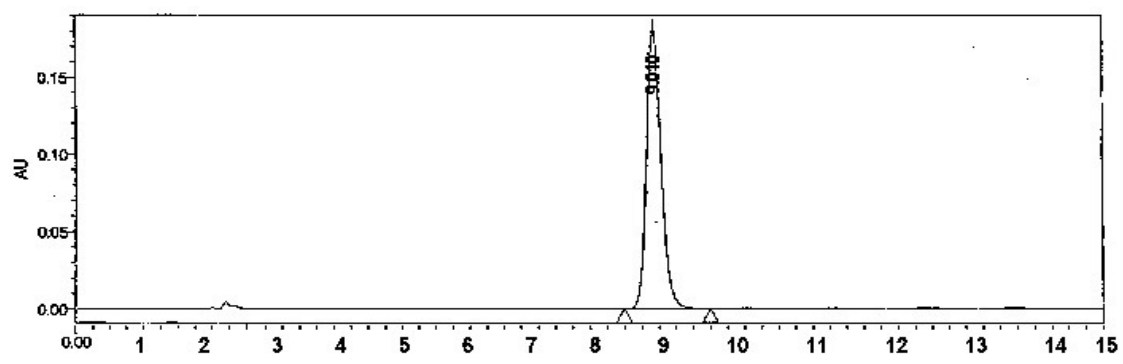

Fig. 5c: Chromatogram of ticagrelor standard solution after 1 w 


\section{Selection of mobile phase and stationary phase}

According to the observations of peak shape and retention time (fig. 6), a flow rate of $1.3 \mathrm{ml}$ and loading volume $10 \mu \mathrm{l}$ was selected. Based on the data table 5, acetonitrile: formic acid: triethylamine in water $50: 50 \mathrm{v} / \mathrm{v}(0.5 \mathrm{ml}: 0.5 \mathrm{ml})$ was selected as the mobile phase for the analysis (fig. 7). A variety of columns with different attributes like polarity, particle size, carbon loading and dimensions were screened in an effort to arrive at the best column for developing the analytical method of ticagrelor in API and tablet formulation (table 6) Akzonobel Kromasil ${ }^{\odot} \mathrm{C} 18150 \times 4.6 \mathrm{~mm} 5 \mu$ was selected as the column for the analysis of ticagrelor (fig. 8a-8b).

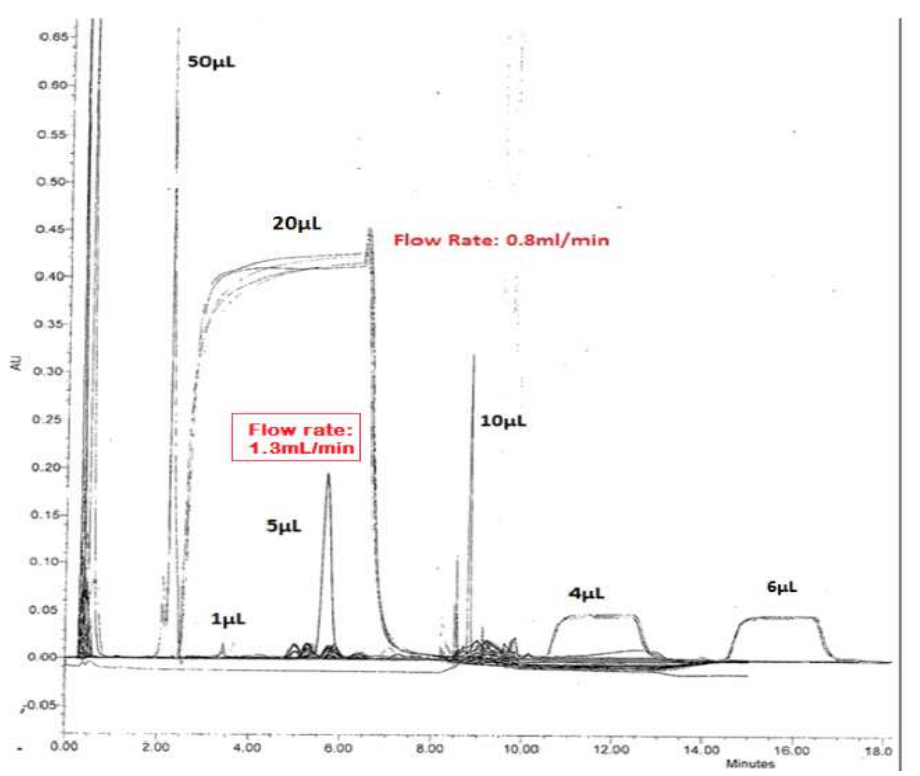

Fig. 6: Effect of flow rate and loading volume on peak shape

Table 5: Effect of mobile phase composition on chromatogram

\begin{tabular}{|c|c|c|c|}
\hline \multirow{2}{*}{$\begin{array}{l}\text { S. } \\
\text { No }\end{array}$} & \multirow[t]{2}{*}{ Mobile phase composition } & \multicolumn{2}{|l|}{ Observation } \\
\hline & & Retention time (min) & peak shape \\
\hline 1 & Acetonitrile: water in 50: $50 \mathrm{v} / \mathrm{v}$. & 8.913 & Tailing \\
\hline 2 & Acetonitrile: water $90: 10 \mathrm{v} / \mathrm{v}$. & 6.341 & Sharp \\
\hline 3 & Acetonitrile: water in $60: 40 \mathrm{v} / \mathrm{v}$ & 9.009 & Tailing \\
\hline 4 & Acetonitrile: water in $40: 60 \mathrm{v} / \mathrm{v}$ & 12.252 & Sharp \\
\hline 5 & Acetonitrile: water $10: 90 \mathrm{v} / \mathrm{v}$ & 11.472 & Shoulder \\
\hline 6 & Acetonitrile: methanol: water $80: 10: 10 \mathrm{v} / \mathrm{v}$. & 9.001 & Sharp \\
\hline 7 & Acetonitrile: methanol: water 50: $25: 25 \mathrm{v} / \mathrm{v}$. & 7.882 & Sharp \\
\hline 8 & Acetonitrile: methanol: water 30: 40:30 v/v. & 9.624 & Sharp \\
\hline 9 & Acetonitrile: methanol: water 40: 30: $30 \mathrm{v} / \mathrm{v}$. & 12.113 & Sharp \\
\hline 10 & Acetonitrile: methanol: water 10: 45: $45 \mathrm{v} / \mathrm{v}$. & 8.624 & Sharp \\
\hline 11 & Acetonitrile: triethyl amine in water (TEA buffer) $50: 50 \mathrm{v} / \mathrm{v} 0.25 \mathrm{ml}$ & 9.991 & Tailing \\
\hline 12 & Acetonitrile: triethyl amine in water (TEA buffer) $50: 50 \mathrm{v} / \mathrm{v} 0.5 \mathrm{ml}$. & 9.100 & Tailing \\
\hline 13 & Acetonitrile: formic acid: triethyl amine in water $50: 50 \mathrm{v} / \mathrm{v} 0.25 \mathrm{ml}: 0.25 \mathrm{ml}$. & 9.931 & Sharp \\
\hline 14 & Acetonitrile: formic acid: triethyl amine in water $50: 50 \mathrm{v} / \mathrm{v} 0.5 \mathrm{ml}: 0.5 \mathrm{ml}$ & 9.434 & sharp \\
\hline 15 & Acetonitrile: buffer $\mathrm{pH} 3.0$ in $50: 50 \mathrm{v} / \mathrm{v}$ & 7.021 & Merged \\
\hline 16 & Acetonitrile: buffer $\mathrm{pH} 4.5 \mathrm{in} 50: 50 \mathrm{v} / \mathrm{v}$ & 9.982 & Merged \\
\hline 17 & Acetonitrile: buffer $\mathrm{pH} 6.8$ in 50:50 v/v. & 3.718 & Tailing \\
\hline 18 & Acetonitrile: buffer $\mathrm{pH} 7.5$ in $50: 50 \mathrm{v} / \mathrm{v}$. & - & - \\
\hline
\end{tabular}

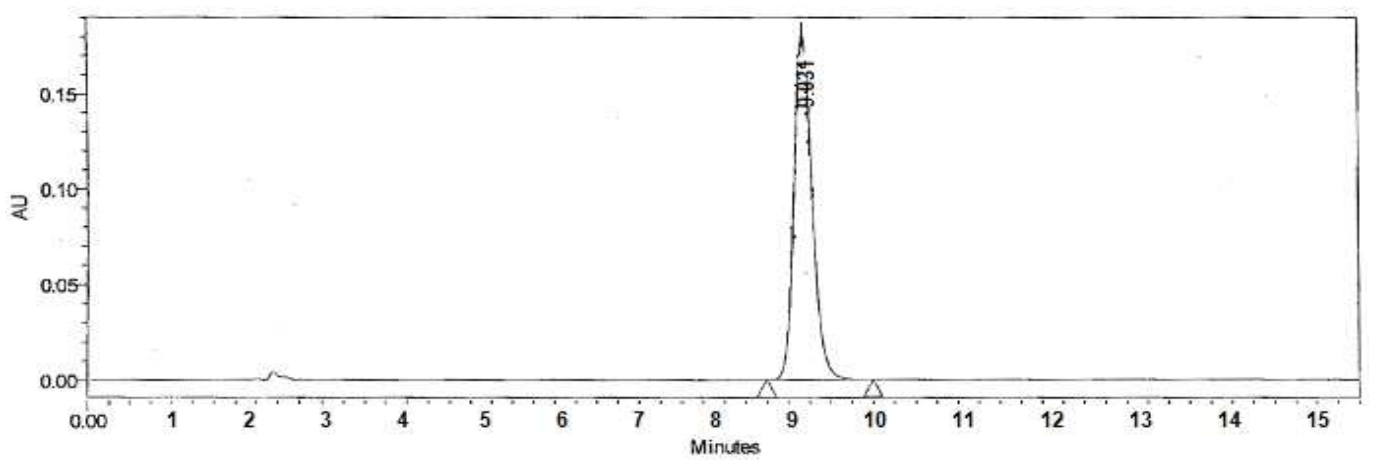

Fig. 7: Chromatogram of ticagrelor with acetonitrile: formic acid: triethylamine in water $50: 50 \mathrm{v} / \mathrm{v}$ (0.5 ml: $0.5 \mathrm{ml}$ ) as mobile phase 
Table 6: Effect of stationary phase on chromatogram

\begin{tabular}{|c|c|c|c|}
\hline \multirow[t]{2}{*}{ S. No. } & \multirow[t]{2}{*}{ Stationary phase } & \multicolumn{2}{|l|}{ Observation } \\
\hline & & Retention time (min) & peak shape \\
\hline 1 & Symmetry ${ }^{\odot} \mathrm{C} 1850 \times 4.6 \mathrm{~mm} 3.5 \mu$ & 9.850 & Sharp \\
\hline 2 & Waters Xterra ${ }^{\odot} \mathrm{C} 18150 \times 4.6 \mathrm{~mm} 3.5 \mu$ & 8.989 & Broad peak \\
\hline 3 & Fortis ${ }^{\oplus} \mathrm{C} 850 \times 4.6 \mathrm{~mm} 5 \mu$ & 8.989 & Symmetric \\
\hline 4 & Inertsil ODS ${ }^{\odot} \mathrm{C} 18250 \times 4.6 \mathrm{~mm} 5 \mu$ & 9.434 & Sharp \\
\hline 5 & AkzonobelKromasil ${ }^{\odot} \mathrm{C} 18150 \times 4.6 \mathrm{~mm} 5 \mu$ & 9.001 & Sharp \\
\hline 6 & BDS Hypersil thermo ${ }^{\circledR} \mathrm{C} 850 \times 4.6 \mathrm{~mm} 5 \mu$ & 13.001 & Fronting \\
\hline 7 & $\mathrm{YMC}^{\odot} \mathrm{C} 18150 \times 4.6 \mathrm{~mm} 5 \mu$ & 14.101 & Broad peak \\
\hline 8 & SupelcosilSupelco ${ }^{\odot} \mathrm{C} 18300 \times 3 \mathrm{~mm} 3 \mu$ & 9.130 & Sharp peak \\
\hline 9 & Hypersil Thermo ${ }^{\circledR} \mathrm{C} 18300 \times 3 \mathrm{~mm} 5 \mu$ & 8.022 & Sharp peak \\
\hline 10 & Agilent ZORBAX ${ }^{\odot} S B$ C18 $150 \times 4.6 \mathrm{~mm} 5 \mu$ & 9.031 & Sharp \\
\hline 11 & Agilent zorbax ${ }^{\oplus} R X \mathrm{C} 18150 \times 4.6 \mathrm{~mm} 5 \mu$ & 7.812 & Sharp \\
\hline 12 & Synergy Hydro Phenomenex ${ }^{\odot}$ C18 $50 \times$ mm $5 \mu$ & 7.992 & Broad peak \\
\hline
\end{tabular}

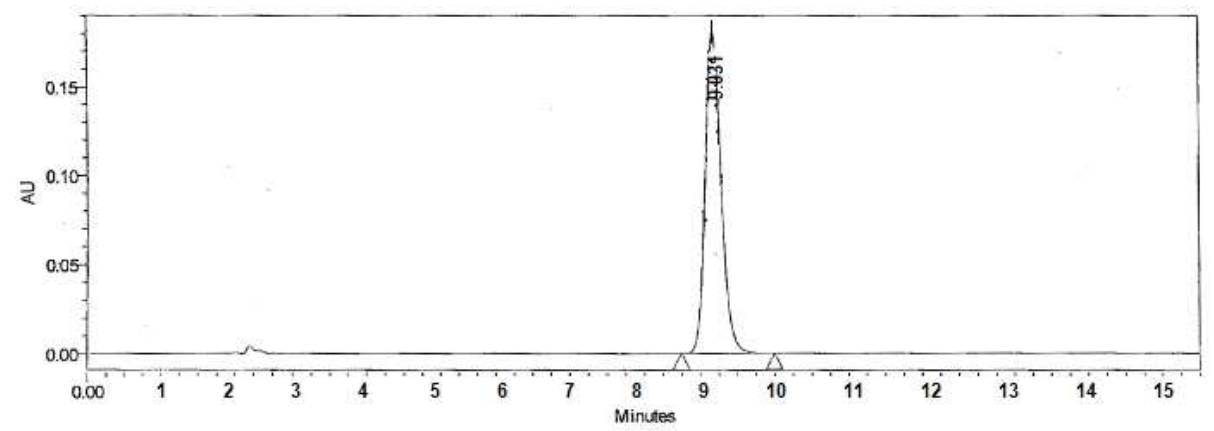

Fig. 8a: Chromatogram of ticagrelor using Inertsil ODS ${ }^{\odot} \mathrm{C18} 250 \times 4.6 \mathrm{~mm}, 5 \mu$

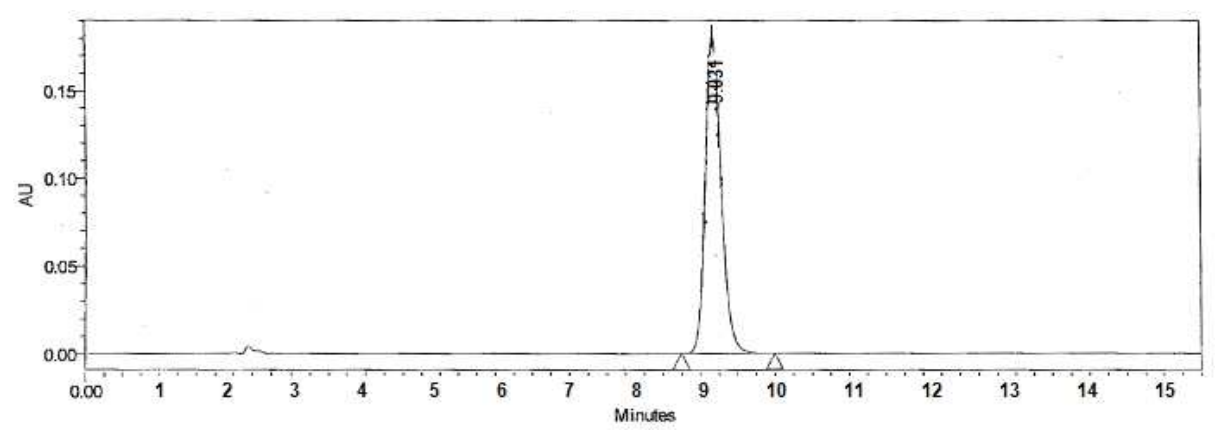

Fig. 8b: Chromatogram of ticagrelor using akzonobel Kromasil ${ }^{\odot} \mathrm{C18} 150 \times 4.6 \mathrm{~mm}, 5 \mu$

Selection of dissolution media by biopharmaceutical classification system (BCS)

Ticagrelor is a class BCS IV drug hence the selection of the solvent for dissolution studies of ticagrelor tablets was crucial. After a series of trials using different solvents (table 7) $0.2 \%$ tween 80 was selected as the solvent (fig. 9).

\section{Dissolution studies and assay of ticagrelor tablets}

The results of dissolution studies indicated that the developed RPHPLC method was suitable for this purpose (table 8). The dissolution results indicated a release of $99.4 \%$ in $60 \mathrm{~min}$. at $75 \mathrm{rpm}$ (fig. 10a). The assay of ticagrelor tablets was conducted using the developed and validated RP-HPLC method and the drug content was found to be $99.9 \%$ (fig. 10b).

Table 7: Effect of various media on the stability of ticagrelor

\begin{tabular}{|c|c|c|c|c|}
\hline \multirow[t]{2}{*}{ S. No. } & \multirow[t]{2}{*}{ Solvent } & \multicolumn{2}{|l|}{ Peak area } & \multirow[t]{2}{*}{$\%$ content } \\
\hline & & Standard & Sample & \\
\hline 1 & Distilled water & - & - & No peak \\
\hline 2 & $0.1 \mathrm{~N} \mathrm{HCl}$ & 1921 & 1850 & 101.23 \\
\hline 3 & pH 4.5 buffer & 10421 & 10393 & 99.73 \\
\hline 4 & pH 6.8 buffer & 120105 & 121021 & 100.283 \\
\hline 5 & pH 7.5 buffer & - & - & No peak \\
\hline 6 & $0.1 \%$ SLS & 1042301 & 1042498 & 99.63 \\
\hline 7 & $0.2 \%$ SLS & 1042598 & 1042502 & 10.00 \\
\hline 8 & $0.1 \%$ Tween 80 & 1075400 & 1075412 & 99.61 \\
\hline 9 & $0.2 \%$ Tween 80 & 1134682 & 1132817 & 99.48 \\
\hline
\end{tabular}




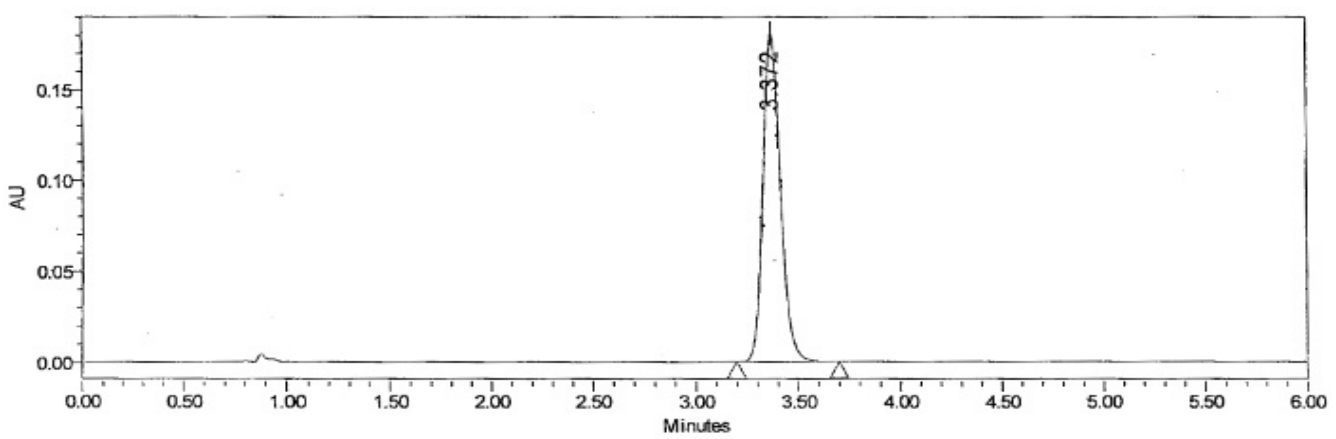

Fig. 9: Chromatogram of ticagrelor in $0.2 \%$ tween 80 in water as solvent

Table 8: Release studies of ticagrelor in $0.2 \%$ tween 80

\begin{tabular}{|c|c|c|c|c|}
\hline \multirow[t]{2}{*}{ S. No. } & \multirow[t]{2}{*}{ Time (min) } & \multicolumn{2}{|l|}{ Peak area } & \multirow[t]{2}{*}{$\%$ release } \\
\hline & & Standard & Sample & \\
\hline 1 & 5 & 1134680 & 481342 & 42.26 \\
\hline 2 & 10 & 1134680 & 501212 & 44.02 \\
\hline 3 & 15 & 1134680 & 541822 & 47.58 \\
\hline 4 & 30 & 1134680 & 755817 & 66.38 \\
\hline 5 & 45 & 1134680 & 1084912 & 95.27 \\
\hline 6 & 60 & 1134680 & 1132817 & 99.48 \\
\hline
\end{tabular}

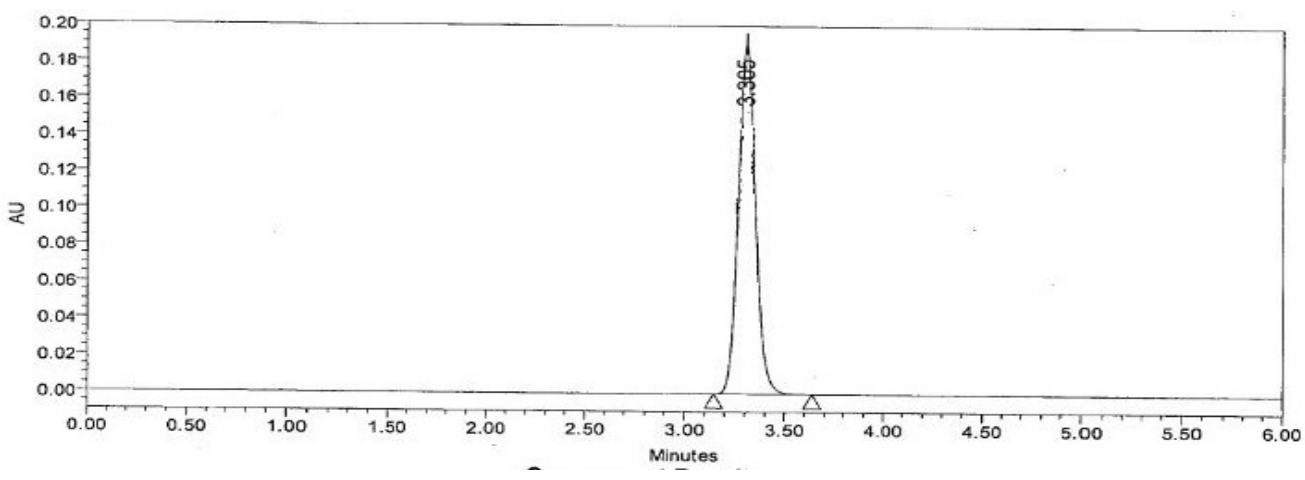

Fig. 10a: Chromatogram of ticagrelor showing release in $60 \mathrm{~min}$. (Dissolution test)

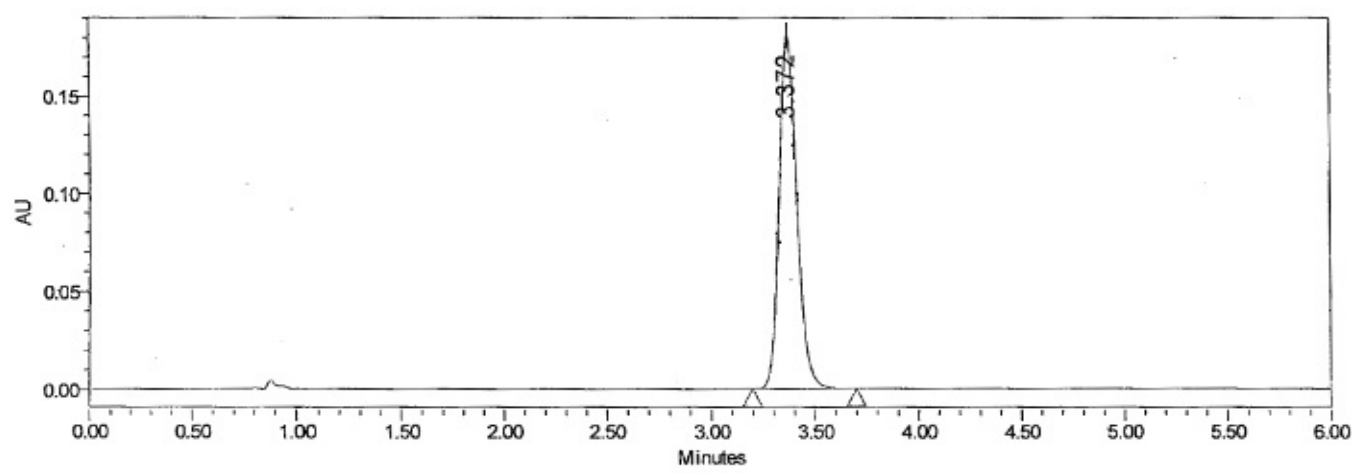

Fig. 10b: Chromatogram of ticagrelor sample (assay)

\section{Related substances (RS) and forced degradation studies (FD)}

The modified gradient RP-HPLC method with a run time of $40 \mathrm{~min}$ run was used for the determination of related substances in ticagrelor tablets after conducting the forced degradation studies. This method was found to be capable of resolving ticagrelor from thirteen related substances (fig. 11).
The modified analytical method with a run time of 12.0 min was used for the determination of impurities generated in the ticagrelor API sample after conducting forced degradation using various stressors. The results obtained (table 9) indicated that the developed method was able to resolve all the degradation peaks from the ticagrelor (fig 12a-12f). 


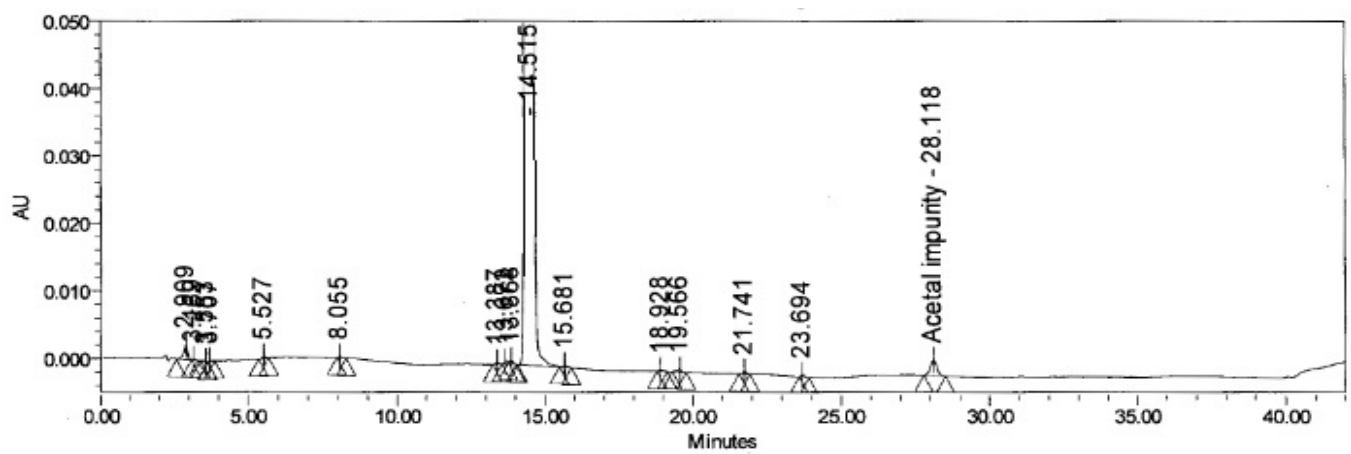

Fig. 11: Chromatogram of ticagrelorat 14.515 min with 13 related substances (RS)

Table 9: Forced degradation studies of ticagrelor

\begin{tabular}{llll}
\hline S. No. & Stressor condition & Retention time of API (min) & Impurities generated \\
\hline 1. & Thermostability & 6.071 & 3 \\
2 & Photostability & 6.076 & 3 \\
3 & Hydrolytic degradation & 6.102 & 10 \\
4 & Oxidative degradation & 6.100 & 11 \\
5 & Acid hydrolysis & 6.089 & 13 \\
& & & and 1 Major impurity at 6.730 min \\
6 & Alkaline hydrolysis & 6.085 & 19 \\
\hline
\end{tabular}

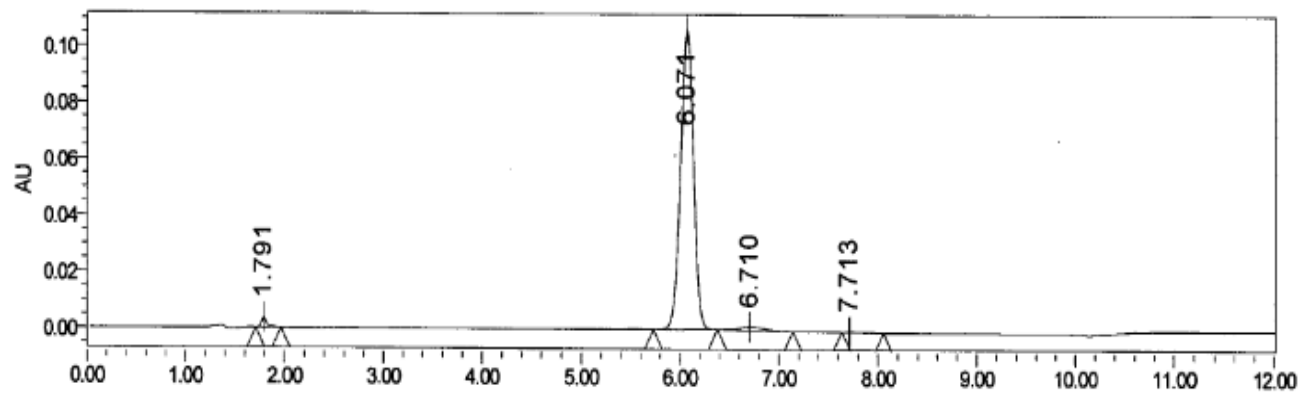

Fig. 12a: Chromatogram of ticagrelor (thermal stability)

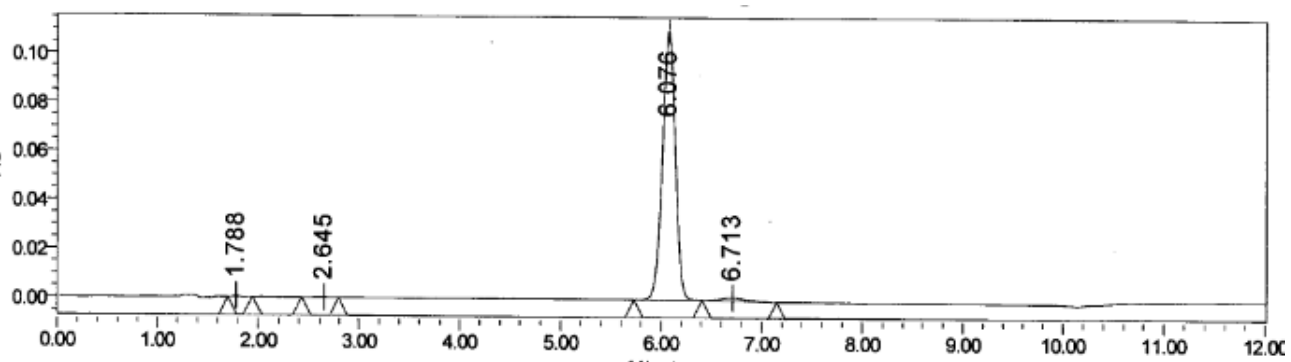

Fig. 12b: Chromatogram of ticagrelor (photostability)

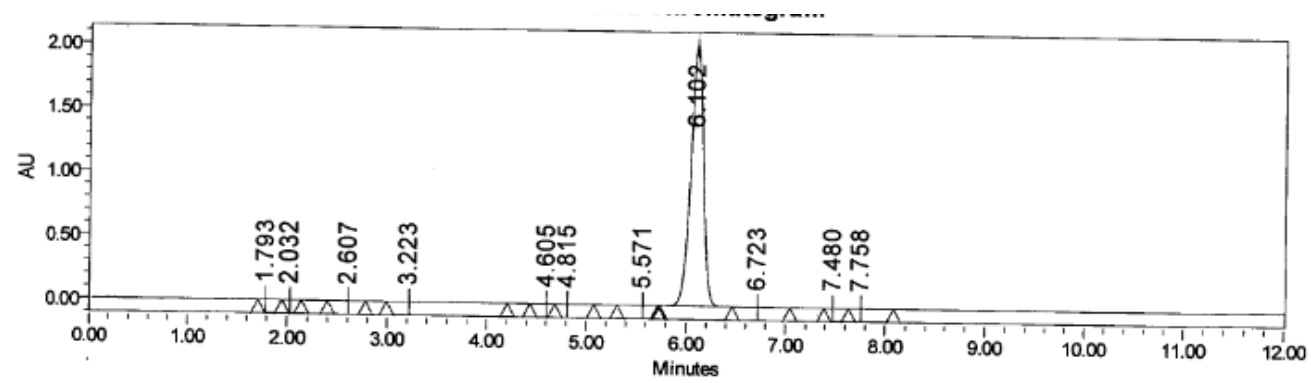

Fig. 12c: Chromatogram of ticagrelor (hydrolytic degradation) 


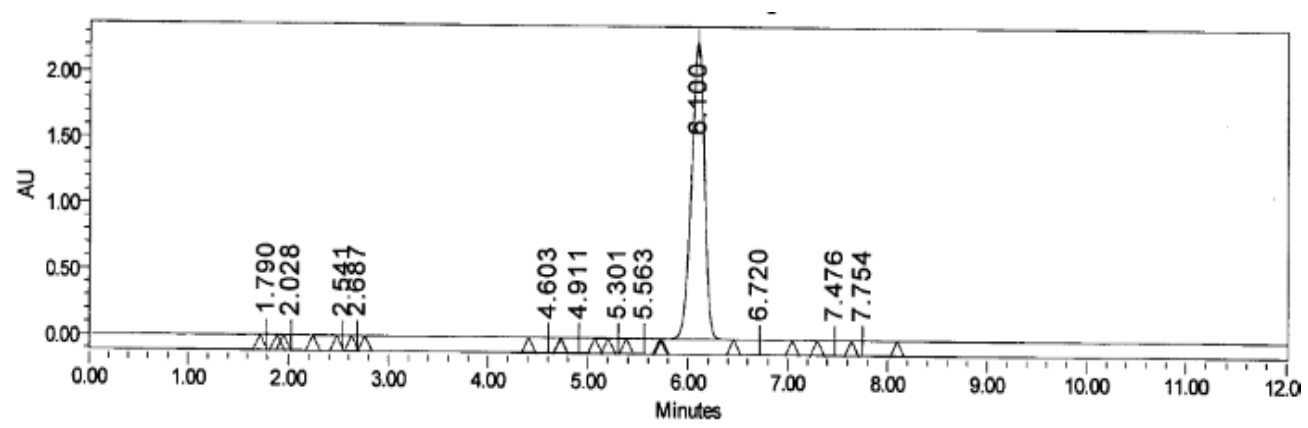

Fig. 12d: Chromatogram of ticagrelor (oxidative degradation)

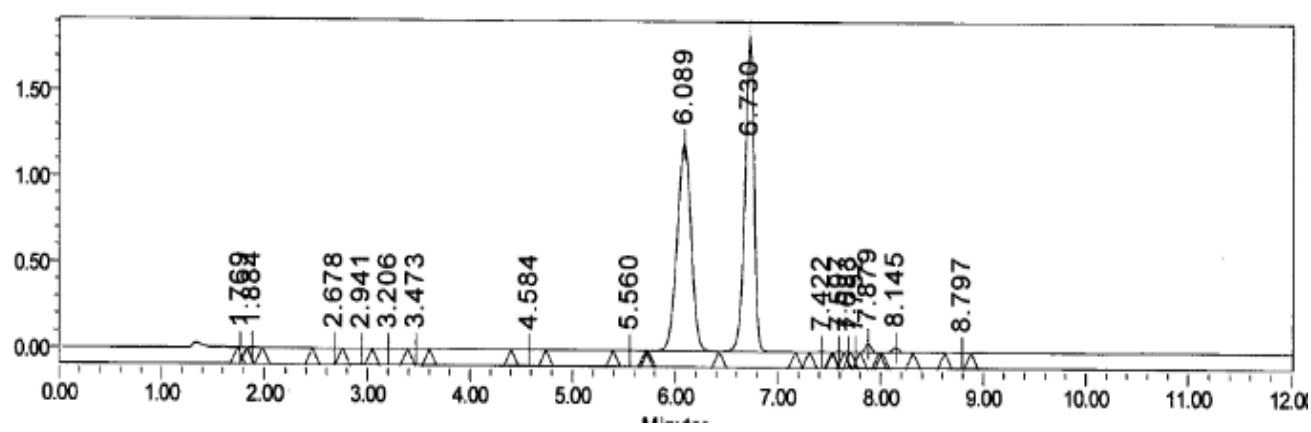

Fig. 12e: Chromatogram of ticagrelor (acid hydrolysis)

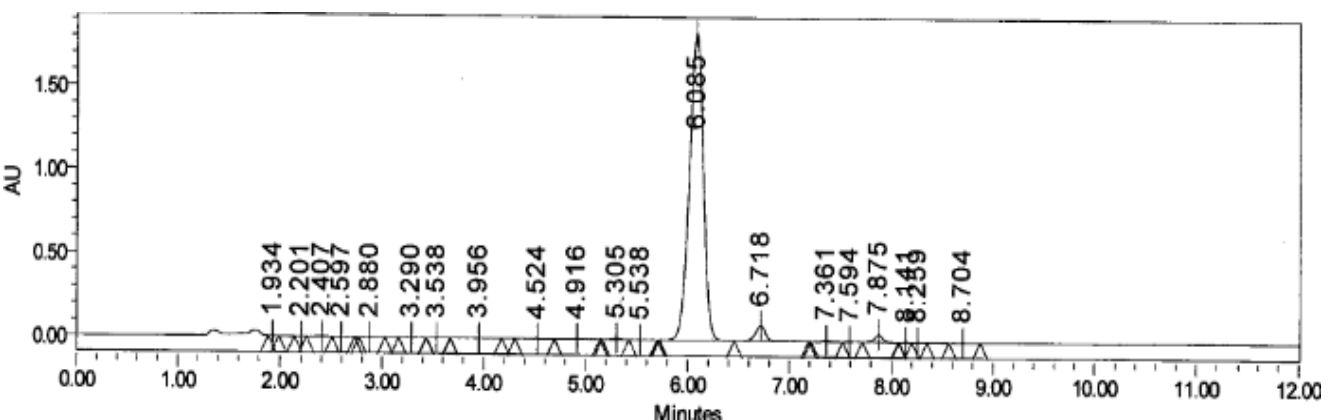

Fig. 12f: Chromatogram of ticagrelor (alkaline hydrolysis)

\section{Validation studies}

The developed RP-HPLC method was validated according to the International Conference on Harmonization (ICH) Q2 guidelines for various parameters like accuracy, precision, specificity, linearity and range, LOD and LOQ, robustness and system suitability.

\section{Accuracy}

The accuracy of the developed method was evaluated by conducting recovery studies. The accuracy was calculated by assay method at concentrations of $50 \%, 100 \%$ and $150 \%$. The calculated amount of ticagrelor stock solutions were spiked to get the concentrations. The $\%$ mean recovery of spiked samples was found to be $99.82 \%$ (table 10).

\section{Precision}

The intra-day precision studies were performed using ticagrelor reference standard solution of $90 \mathrm{ppm}$. The solution was injected at various time intervals and percent related standard deviation (\% RSD) was determined. The inter-day precision was studied by injecting the same concentration of standard solution on consecutive days and the \% RSD was calculated. The relative standard deviation obtained from 12 assay results was found to be $0.069 \%$ (table 11 ).

Table 10: Accuracy studies of ticagrelor

\begin{tabular}{|c|c|c|c|c|}
\hline Level & Conc. added $(\mu \mathrm{g} / \mathrm{ml})$ & Conc. found $(\mu \mathrm{g} / \mathrm{ml})$ & \% recovery & \% mean recovery \\
\hline \multirow[t]{3}{*}{$50 \%$} & 45.051 & 44.51 & 99.80 & \\
\hline & 45.042 & 44.96 & 99.82 & $99.79 \%$ \\
\hline & 45.064 & 44.96 & 99.76 & \\
\hline \multirow[t]{3}{*}{$100 \%$} & 90.01 & 90.01 & 100.0 & \\
\hline & 89.92 & 89.84 & 99.91 & $99.93 \%$ \\
\hline & 90.04 & 90.01 & 99.90 & \\
\hline \multirow[t]{3}{*}{$150 \%$} & 135.012 & 134.674 & 99.74 & \\
\hline & 135.003 & 134.74 & 99.80 & $99.75 \%$ \\
\hline & 135.014 & 134.62 & 99.71 & \\
\hline
\end{tabular}


Table 11: Precision studies of ticagrelor

\begin{tabular}{|c|c|c|c|c|c|c|}
\hline \multirow[t]{2}{*}{ Precision parameter } & \multicolumn{4}{|c|}{ Peak area } & \multirow[t]{2}{*}{ SD } & \multirow[t]{2}{*}{ \% RSD } \\
\hline & Run 1 & Run 2 & Run 3 & Mean & & \\
\hline Reproducibility & 1389984 & 1389953 & 1388300 & 1389412 & 963.433 & 0.069 \\
\hline Intermediate precision & 1389986 & 1389958 & 1388303 & 1389416 & 963.699 & 0.069 \\
\hline repeatability & 1389983 & 1389956 & 1388309 & 1389416 & 958.785 & 0.069 \\
\hline
\end{tabular}

Table 12: Specificity studies of ticagrelor

\begin{tabular}{lll}
\hline S. No. & Standard (Area AU) & Sample (Area AU) \\
\hline 1 & 138668 & 138650 \\
2 & 138764 & 138758 \\
3 & 138599 & 138596 \\
Mean & 138677 & 138668 \\
SD & 82.86736 & 82.48636 \\
\%RSD & 0.059756 & 0.059485 \\
\hline
\end{tabular}

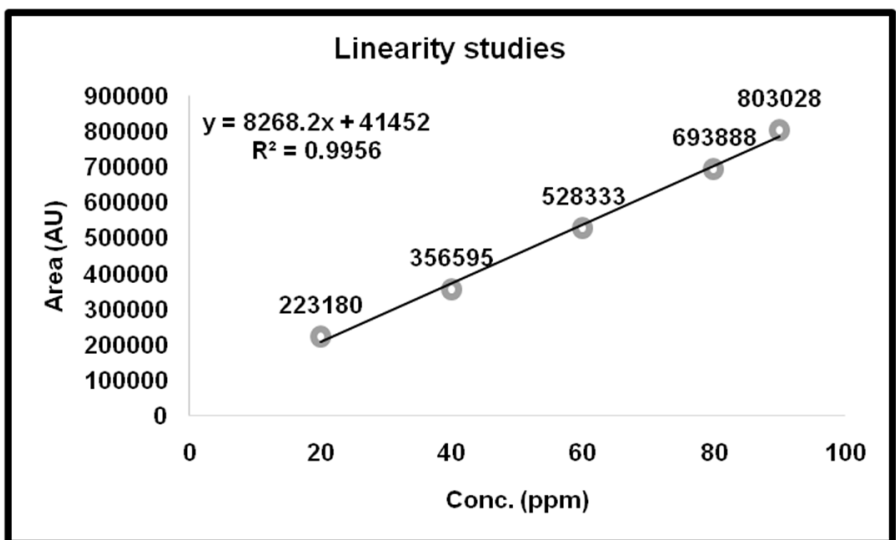

Fig. 13: Linearity and range studies of ticagrelor

\section{Specificity}

No interferences were observed in the chromatogram of ticagrelor standard due to the presence of excipients and blank (table 12).

\section{Linearity and range}

A graph of peak area versus concentration (ppm) were plotted for ticagrelor at concentration range between 20-90 ppm. The linear regression equation and correlation coefficient $\left(r^{2}\right)$ were $y=$ $8268.2 x+41452$ and 0.995 respectively (fig. 13).

\section{LOD and LOQ}

The results of signal to noise ratio was compared with the response of ticagrelor standard. The LOD and LOQ were found to be 0.2887 ppm and 0.8749 ppm respectively.

\section{System suitability}

System suitability tests were performed using ticagrelor standard and test solutions to check for compliance with specified parameters (table 13).

Table 13: System suitability studies of ticagrelor

\begin{tabular}{lll}
\hline S. No. & Parameter & Ticagrelor \\
\hline 1 & Retention time & 3.305 \\
2 & Number of theoretical plates & 5538 \\
3 & Tailing factor & 0.85 \\
4 & Peak area & 1134680 \\
5 & Peak height & 190457 \\
\hline
\end{tabular}

Table 14: Robustness studies of ticagrelor

\begin{tabular}{llll}
\hline Factor & Level & $\mathbf{T}_{\mathbf{R}}$ & Tailing factor \\
\hline Parameter: Flow rate & & & 3.53 \\
$1.2 \mathrm{ml} / \mathrm{min}$ & -1 & 3.31 & 0.86 \\
$1.3 \mathrm{ml} / \mathrm{min}$ & 0 & 3.20 & 0.92 \\
$1.4 \mathrm{ml} / \mathrm{min}$ & +1 & $\mathbf{3 . 3 4}$ & 0.74 \\
Mean & & & $\mathbf{0 . 8 4}$ \\
Parameter: Column temperature & & 3.48 & 0.75 \\
$25{ }^{\circ} \mathrm{C}$ & -5 & 3.32 & 0.88 \\
$30{ }^{\circ} \mathrm{C}$ & 0 & 3.14 & 0.81 \\
$35{ }^{\circ} \mathrm{C}$ & +5 & $\mathbf{3 . 3 1}$ \\
Mean & & & $\mathbf{0 . 7 9}$ \\
\hline
\end{tabular}




\section{Robustness studies}

The changes were applied and system suitability parameters were checked, found to be within the acceptable limits. It was noted that trivial changes in temperature and flow rate does not affect the method and produces results which passes system suitability. Hence the method was robust (table 14).

\section{CONCLUSION}

A new RP-HPLC method for the determination of ticagrelor was developed and validated. The developed method was accurate, precise, specific and sensitive for the quantitative analysis of ticagrelor both in bulk drug and tablets. Validation studies indicated the method to be robust on minor variations in the chromatographic parameters. No attempt was made to quantify the degradation products in this research project. This method can be used for routine quality monitoring of ticagrelor and its tablets. This method can be extended for application in LC-MS for quantitative estimation of known and unknown impurities generated during forced degradation and related substance studies both for API and finished products of ticagrelor.

\section{CONFLICT OF INTERESTS}

Declared none

\section{REFERENCES}

1. Bassam A, Rasool H. HPLC uses and importance in the pharmaceutical analysis and industrial field. Pharm Anal Acta 2012;3:9.

2. Wilmington LP, Astra Zeneca. Drug detailing cardiovascular and renal drug advisory committee meeting, Set III, CC-1; 2010.

3. Gurbel PA. Randomized double-blind assessment of the ONSET and OFFSET of the antiplatelet effects of drug versus clopidogrel in patients with stable coronary artery disease. Circulation 2009;22;120:2577-85.

4. Highlights of prescribing information, AstraZeneca 2943105, Initial US approval; 2011
5. Ambasana Mrunal. Development and validation of a UV spectrophotometric method for the determination of drug in bulk form. Scholars Res Library 2014;6:237-40.

6. L Lakshmana Rao. A validated stability-indicating HPLC method for determination of drug in bulk and its formulation. Int J Pharm 2013;3:634-42.

7. White house laboratories. Available from: http:// whitehouselabs.com/blog/18/high-performance-liquidchromatography-hplc-testing. [Last Accessed on 01 Jan 2017]

8. HPLC: Determination of contents of addition in drugs. Available from: http://intranet.tdmu.edu.ua/data/kafedra/internal/ pharma _2/classes_stud/en/pharm/prov_pharm/ptn/analytical\%20chemi stry/2\%20course/25\%20HIGH. [Last Accessed on 01 Jan 2017]

9. Blogspot. In HPLC. Available from: http://hplc-hplc. blogspot.in/. [Last Accessed on 01 Jan 2017]

10. Jagnmohanarao: Pharmaceutical dosage forms Quality ControlAnalytical Method validation. Available from: http://www. jaganmohanarao.com/. [Last Accessed on 01 Jan 2017]

11. FDA Govt. Guidance: Assay method validation definition and terms Sci; 2005. Available from: http://www.fda.gov/ downloads/Drugs/Guidances/ucm073381.pdf. [Last Accessed on 01 Jan 2017]

12. ICH Guidelines for stability of new drug substances and products. Q1A (R2) ICH, Geneva; 2005. p. 1-13.

13. ICH guidelines for validation of analytical procedures: text and methodology. Q2 (R1) ICH, Geneva; 2005. p. 1-14.

14. Jayaprakash. Stability indicating method development and validation for the simultaneous determination of vidagliptin and metformin in pharmaceutical dosage form. Int J Pharm Pharm Sci 2017;9:150-7.

15. Nazneen. Development of assay method and forced degradation study of valsartan and sacubitril by RP-HPLC in tablet formulation. Int J Appl Pharm 2017;9:9-15.

\section{How to cite this article}

- $\quad$ K Tabassum, R Sarvesh. Analytical method development and validation studies of ticagrelor tablets by RP-HPLC. Int J Appl Pharm 2017;9(4):10-21. 